\title{
Impacts Of Vocabulary Acquisition Techniques Instruction On Students' Learning
}

Wiwat Orawiwatnakul, Bangkok University, Thailand

\begin{abstract}
The objectives of this study were to determine how the selected vocabulary acquisition techniques affected the vocabulary ability of 35 students who took EN 111 and investigate their attitudes towards the techniques instruction. The research study was one-group pretest and post-test design. The instruments employed were in-class exercises regarding an analysis of word structures and context clues, a vocabulary proficiency test, as well as a questionnaire surveying the students' attitudes toward the instruction. The pretest and post-test scores were calculated for descriptive statistics and compared using a t-test dependent measure. The study revealed that the students' post-test score was higher than their pretest score at the .001 level of significance. The results of the questionnaire also illustrated their very favorable attitude toward the instruction of vocabulary acquisition techniques as a whole.
\end{abstract}

Keywords: vocabulary learning; teaching vocabulary

\section{INTRODUCTION}

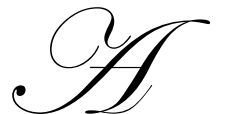

s learners of English as a foreign language, Thai students have to overcome quite a lot of stumbling blocks, not the least of which is vocabulary. In fact, for many students, vocabulary poses the greatest threat of all. They cannot get their messages across because they do not possess adequate vocabulary to make what they want to convey understood. Vocabulary plays an important role in language learning. Many students cannot do well in English as they possess a small vocabulary size.Vocabulary is a core component of language proficiency and provides much of the basis for how well learners speak, listen, read, and write. This idea can be supported by Nation (2001, p.114) suggesting an amount of vocabulary needed in order to comprehend a text, saying that "Learners would need at least 95\% coverage of the running words in the input in order to gain reasonable comprehension and to have reasonable success at guessing from context." Therefore, learners will be able to use vocabulary efficiently if they know enough words. Vocabulary is important for reading achievement in the university level due to the increasing demands of the texts students are required to read in their specific area. In addition, for productive skills like speaking and writing, if learners don't have an adequate number of words, they cannot convey their message.

In an attempt to resolve this problem, many teachers try to find the most appropriate method of learning vocabulary for students, hoping to help them utilize that particular method no matter what vocabulary they encounter such as reading plus vocabulary enhancement activities (Min, 2008). Ellis (2002, p.179) proposed that frequency is a fundamental feature of cognitive processing and acquisition. The words occurring often tend to be remembered and learned. Moreover, saliency also helps to increase vocabulary knowledge; the more a form stands out in the input stream, the more likely it will be noticed (Schmidt, 1995). This concept was supported by Watson (2003), stating that a teacher can increase word or phrase saliency by writing on the board, spelling of words, and asking questions about certain words. Many strategies were suggested by educators who studied ways to improve learners' vocabulary skill. Schmitt (1997) developed his vocabulary learning taxonomy based on Oxford's wellknown language learning strategy taxonomy. He acquired two classes: discovery strategies and consolidation strategies. Discovery strategies are strategies used for gaining initial information about a new word. They include 
two main strategies: determination strategies and social strategies. In contrast, consolidation strategies which are used for remembering a word once it has been introduced contain four groups: social strategies, memory strategies, cognitive strategies, and metacognitive strategies.

In addition, some researchers have found out that the success of explicit teaching of vocabulary was greatly influenced by breaking words into their components parts such as teaching word formation knowledge on sentence restatement and inferencing (Emadin \& Moghadam, 2007) and using vocabulary learning exercises (Tabtimsai, 2003). Also, teaching students how to use context clues while reading improves their understanding of new vocabulary words (Yuen, 2009). Using task-based activities can improve students' vocabulary learning and their confidence (Summat, 2009). These results were found to be successful in enhancing students' vocabulary knowledge.

For the undergraduate level at Bangkok University, nine faculties including Humanities, Business Administration, Accounting, Communication Arts, Fine and Applied Arts, Sciences, and Engineering, are required to take at least three Fundamental English courses. Also, students in each class have different levels of language proficiency. During their first year at Bangkok University, the freshmen are in a big trouble when they are assigned to read more in English. A limited vocabulary makes them encounter the problem of text comprehension. If they have more vocabulary knowledge, they are likely to be more successful in their learning. Accordingly providing students with more vocabulary is the most appropriate method to help them improve their English vocabulary skill. The researcher believes that for most students any one particular technique of learning vocabulary may not prove efficient enough. A combination of certain techniques might enable students to better acquire and retain words unknown to them. Therefore, this research was conducted to investigate the effects of vocabulary acquisition techniques instruction on students' vocabulary knowledge as well as to explore their attitudes towards using the techniques.

\section{RESEARCH QUESTIONS}

This study addressed the following issues:

1. To what extent did the selected vocabulary acquisition techniques contribute to the students' improvement of their vocabulary acquisition?

2. What are their attitudes towards teaching these techniques as a whole?

\section{RESEARCH METHODOLOGY}

\section{1) Research Design}

This study employed the one group pre-test post-test design. The data were collected from one section containing 35 students enrolled in a required EN 111 course of 3 credits in the first semester of 2010 academic year through cluster sampling since students were already assigned to their sections

\section{2) Instrument}

Three instruments were used in this study. These were 1) the pretest and the post-test, 2) exercises for vocabulary acquisition, and 3 ) the questionnaire for gathering information about the students' attitudes towards the instruction of in-class vocabulary acquisition techniques.

To study the students' vocabulary learning, the same test was used as a parallel test for pre-and post-testing. The pretest and post-test questions were comprised of 50 multiple-choice questions which tested the students on vocabulary. The words and the question formats were specifically chosen to test the students on their knowledge of vocabulary and the learning techniques learned through the techniques. It was designed to assess the students' vocabulary proficiency, covering the content of word structures like roots, prefixes, suffixes, compound words and guessing meaning from context from five ways: definition, restatement, comparison, contrast, example, and synonym. This vocabulary test had been examined by three teachers of English, later revised for correctness, and 
piloted with 40 students to examine the proper difficulty and discrimination values. In addition, the exercises of learning techniques were designed based on Torat's concept (2000) with five stages namely, motivation, presentation, practice, transferring activity and evaluation. The exercises asked students to identify prefixes, suffixes, roots, base meaning of compound, definition, restatement, comparison, contrast, examples, and synonyms. For exploring the students' attitudes towards the vocabulary exercises, the questionnaire was adapted from Tabtimsai (2003).

\section{3) Subjects}

The data were collected from one section containing 35 first-year students randomized by cluster sampling from 120 sections. They took the compulsory 3-credit course EN 111 in the first semester of the academic year 2010. Two variables were involved here. The two dependent variables were the students' vocabulary capabilities which were measured by the pretest and the post-test and their attitude towards the instruction which was evaluated by the questionnaire. The independent variable was the instruction of vocabulary acquisition techniques.

\section{4) Vocabulary Acquisition Techniques Instruction}

Although there were many useful strategies and methods employed in previous research to develop students' vocabulary learning, this study was done with an aim to prepare students with encountering new words from various sources. They needed to learn techniques for finding the meaning of vocabulary based on two main types. The first one is called an analysis of word structures concerning roots, prefixes, suffixes, and compound words. The latter was an analysis of context clues where readers can guess the meaning from five ways: definition, restatement, comparison, contrast, example, and synonym.

Word Structure Analysis. When students encounter unfamiliar words, analyzing word structure can prove an effective way to find their meanings. Pittman (2003) asserts that by slowly and steadily studying the most prominent prefixes, roots, and suffixes, students can acquire a vocabulary that is far greater than the sum of its parts. When students analyze a word structure, they break the word into smaller parts or components which may give a hint of what the word means. According to Nagy and others (1992), structural analysis can most easily be defined as the use of word parts to help determine the meaning and pronunciation of words. They also estimate that there are as many as $60 \%$ of English words whose meanings can be guessed from their parts. William E. Nagy, Jean Osborn, Pamela Winsor, and John O'Flahavan go on to say that word structural analysis (1) may also play an important role in remembering the form of new words, (2) may also help students remember the meanings of words, even in cases where the meanings of the parts are not sufficient to reveal the meaning of the whole, (3) can also help with decoding and spelling even when it does not help with meaning, and (4) also benefits readers by allowing them to recognize words more efficiently.

Analysis with Context Clues. The use of context clues plays a vital role in language acquisition. Actually most of students' vocabulary acquisition may be attributable to using context clues. Context clues are "the clearly stated or implied words or phrases which help to comprehend unfamiliar words in context because they can activate the corresponding context to clarify the contextual meanings of the words concerned" (Sun \& Zhou, 2005, p.49). Context clues are divided into quite a few types depending on various criteria and individuals. Definition, restatement, comparison and contrast are but a few examples. Yang (2009) concludes in a research that (1) college English teachers should keep the students better informed of the significance and specific functioning of context clues in contextual guessing, and (2) college English teachers should encourage the students to guess word meanings from context instead of inhibiting it when there are adequate context clues offered. But since a word may have several meanings, the use of context clues will prove effective only when a general meaning of a word is adequate. When the surrounding words are not familiar, when the definite meaning is required, or when the word in question is a key word, using context clues might not be a good idea. A dictionary should be consulted.

\section{5) Procedure}

At the beginning of the semester the students were required to do the 50-question pretest testing them on vocabulary usage deemed necessary for first-year students within the time allotted (30 minutes). Each student's 
performance was recorded in terms of points. The pre-test score was used to divide the students into three groups, namely high-, intermediate-, and low-proficiency groups. The cut-point was determined by using Mean $\pm .5 \mathrm{SD}$. The range of the "high" group was higher than 29.71 while the range of the "intermediate" group fell between 17.3429.71. The range of the "low" group was lower than 17.34. Then for the next ten weeks they were taught and drilled in the various techniques of vocabulary acquisition-roots, prefixes, suffixes, compound words, definition, restatement, comparison, contrast, example, and synonym. Detailed explanations were given and exercises were assigned and finished in class. After that the students were given the post-test. The scores from both tests were compared as a way to learn whether and to what extent the vocabulary acquisition techniques impacted on their vocabulary capabilities as well as to find out the significant differences. To examine whether the instruction affected all three groups of proficiency, pre-and post-scores were taken to analyzed. Moreover, in an attempt to learn what the students thought about and how they viewed the in-class vocabulary activities, they were asked to answer a questionnaire after the post-test. The questionnaire aimed at finding out their opinions about the content, activities, and benefits.

\section{RESULTS}

The data obtained from the pre-test/post-test and questionnaire were analyzed by Statistical Packages for the Social Sciences (SPSS). An analysis was done for frequency, percentage, mean scores and paired samples t-test. The results were used to answer the research questions.

Research Question 1: To what extent did the selected vocabulary acquisition techniques contribute to the students' improvement of their vocabulary knowledge?

Table 1 shows that the mean score of the posttest was higher than that of the pretest. As evidenced by the significant difference at the level of .001, it clearly illustrates that the various techniques of vocabulary acquisition studied in class proved rather effective.

Table 1 Means of the Pre-Test and Post-Test of the Students

\begin{tabular}{|c|c|c|c|c|c|}
\hline & $\mathbf{N}$ & $\bar{x}$ & S.D. & $\mathbf{t}$ & \multirow{2}{*}{ Sig } \\
\hline Pretest & 35 & 21.91 & 7.80 & \multirow{2}{*}{$10.42 *$} & .000 \\
\hline Posttest & 35 & 32.91 & 8.09 & .000 \\
\hline
\end{tabular}

$* * \mathrm{p}<.001$

Table 2 The Mean Scores Obtained from Pre-test and Post-test Shown in Three Groups

\begin{tabular}{|l|c|c|c|c|}
\hline \multicolumn{1}{|c|}{ High Group } & N & Mean Scores & t-value & Sig (2-tailed) \\
\hline Pre-test & 6 & 35.67 & $7.06^{*}$ & .001 \\
\hline Post-test & 6 & 41.33 & & \\
\hline Difference & & 5.66 & & \\
\hline Intermediate Group & & & & .000 \\
\hline Pre-test & 17 & 22.18 & & \\
\hline Post-test & 17 & 34.00 & & \\
\hline Difference & & 11.82 & & \\
\hline Low Group & & & & \\
\hline Pre-test & 12 & 14.67 & & \\
\hline Post-test & 12 & 27.17 & & \\
\hline Difference & & 12.50 & & \\
\hline
\end{tabular}

$* \mathrm{p}<.01, * * \mathrm{p}<.001$

In order to find out how much each group of students improved significantly in their vocabulary ability, the pre-test score was used to divide them into three groups; namely high, intermediate, and low. Then the pre-and posttest mean score of each group was compared by using a paired samples t-test. The results indicate that the mean 
scores of the three groups were obviously higher than those obtained from the pre-test (see Table 2). The differences of the mean scores of the high-, intermediate-, and low-reading proficiency groups are 5.66, 11.82, and 12.50 respectively. The t-test results also suggested a statistically significant difference between the pre-test and post-test scores. This indicates that all three groups made good progress in English vocabulary ability after they were taught by these techniques for ten weeks.

Research Question 2: What are their attitude towards the instruction of vocabulary learning techniques in terms of format and content, activities, and benefits?

Table 3: Students' Attitudes towards the Instruction of Vocabulary Learning Techniques Shown in Percentage and Frequency

\begin{tabular}{|c|c|c|c|c|c|c|c|c|}
\hline & Statement & $\begin{array}{l}\text { strongly } \\
\text { agree } \\
\text { agree }\end{array}$ & agree & $\begin{array}{l}\text { neither } \\
\text { agree nor } \\
\text { disagree }\end{array}$ & disagree & $\begin{array}{l}\text { strongly } \\
\text { disagree }\end{array}$ & $\bar{x}$ & SD \\
\hline \multicolumn{9}{|c|}{ Format and Content } \\
\hline 1 & The letters were clear and easy to read. & $\begin{array}{l}31.43 \\
(11)\end{array}$ & $\begin{array}{l}62.86 \\
(22)\end{array}$ & $\begin{array}{l}5.71 \\
(2)\end{array}$ & $\begin{array}{l}0 \\
(0)\end{array}$ & $\begin{array}{c}0 \\
(0)\end{array}$ & 4.26 & .56 \\
\hline 2 & Each step of the presentation was clear. & $\begin{array}{c}22.86 \\
(8) \\
\end{array}$ & $\begin{array}{l}65.71 \\
(23)\end{array}$ & $\begin{array}{c}11.43 \\
(4)\end{array}$ & $\begin{array}{l}0 \\
(0)\end{array}$ & $\begin{array}{l}0 \\
(0)\end{array}$ & 4.11 & .58 \\
\hline 3 & The level of the content suited me. & $\begin{array}{l}5.71 \\
(2)\end{array}$ & $\begin{array}{l}57.14 \\
(20)\end{array}$ & $\begin{array}{l}37.14 \\
(13)\end{array}$ & $\begin{array}{c}0 \\
(0)\end{array}$ & $\begin{array}{c}0 \\
(0)\end{array}$ & 3.69 & .58 \\
\hline 4 & $\begin{array}{l}\text { The amount of content was proportional to } \\
\text { the study time. }\end{array}$ & $\begin{array}{l}8.57 \\
(3)\end{array}$ & $\begin{array}{l}74.29 \\
(26)\end{array}$ & $\begin{array}{c}11.43 \\
(4)\end{array}$ & $\begin{array}{l}5.71 \\
(2)\end{array}$ & $\begin{array}{l}0 \\
(0)\end{array}$ & 3.86 & .65 \\
\hline \multicolumn{9}{|c|}{ Activities } \\
\hline 5 & $\begin{array}{l}\text { The motivation phase enabled me to learn } \\
\text { word structures and contexts. }\end{array}$ & $\begin{array}{c}22.86 \\
(8)\end{array}$ & $\begin{array}{l}64.71 \\
(23)\end{array}$ & $\begin{array}{c}11.43 \\
(4)\end{array}$ & $\begin{array}{l}0 \\
(0)\end{array}$ & $\begin{array}{l}0 \\
(0)\end{array}$ & 4.11 & .58 \\
\hline 6 & $\begin{array}{l}\text { The presentation phase offered explanations } \\
\text { and examples of word structures and } \\
\text { contexts that were clear and easy to } \\
\text { understand. }\end{array}$ & $\begin{array}{c}20.00 \\
(7)\end{array}$ & $\begin{array}{l}60.00 \\
(21)\end{array}$ & $\begin{array}{c}20.00 \\
(7)\end{array}$ & $\begin{array}{l}0 \\
(0)\end{array}$ & $\begin{array}{l}0 \\
(0)\end{array}$ & 4.00 & .64 \\
\hline 7 & $\begin{array}{l}\text { The practice phase afforded word structure } \\
\text { and context exercises. }\end{array}$ & $\begin{array}{c}14.29 \\
(5)\end{array}$ & $\begin{array}{l}60.00 \\
(21)\end{array}$ & $\begin{array}{c}17.14 \\
(6)\end{array}$ & $\begin{array}{l}8.57 \\
(3)\end{array}$ & $\begin{array}{l}0 \\
(0)\end{array}$ & 3.80 & .80 \\
\hline 8 & $\begin{array}{l}\text { The exercises gave me enough knowledge } \\
\text { of word structures and contexts to do the } \\
\text { activities in transfer activity. }\end{array}$ & $\begin{array}{c}17.14 \\
(6)\end{array}$ & $\begin{array}{l}60.00 \\
(21)\end{array}$ & $\begin{array}{c}20.00 \\
(7)\end{array}$ & $\begin{array}{l}2.86 \\
(1)\end{array}$ & $\begin{array}{l}0 \\
(0)\end{array}$ & 3.91 & .70 \\
\hline 9 & $\begin{array}{l}\text { The post-test helped me evaluate what I had } \\
\text { learned. }\end{array}$ & $\begin{array}{c}22.86 \\
(8)\end{array}$ & $\begin{array}{l}65.71 \\
(23)\end{array}$ & $\begin{array}{c}11.43 \\
(4)\end{array}$ & $\begin{array}{l}0 \\
(0)\end{array}$ & $\begin{array}{l}0 \\
(0)\end{array}$ & 4.11 & .58 \\
\hline \multicolumn{9}{|c|}{ Benefits } \\
\hline 10 & $\begin{array}{l}\text { The vocabulary acquisition techniques } \\
\text { increased my knowledge of meanings of } \\
\text { words. }\end{array}$ & $\begin{array}{l}28.57 \\
(10)\end{array}$ & $\begin{array}{l}51.43 \\
(18)\end{array}$ & $\begin{array}{c}17.14 \\
(6)\end{array}$ & $\begin{array}{l}2.86 \\
(1)\end{array}$ & $\begin{array}{l}0 \\
(0)\end{array}$ & 4.06 & .76 \\
\hline 11 & $\begin{array}{l}\text { The vocabulary acquisition techniques } \\
\text { increased my knowledge of word structures } \\
\text { and contexts. }\end{array}$ & $\begin{array}{c}20.00 \\
(7)\end{array}$ & $\begin{array}{l}71.43 \\
(25)\end{array}$ & $\begin{array}{l}8.57 \\
(3)\end{array}$ & $\begin{array}{l}0 \\
(0)\end{array}$ & $\begin{array}{l}0 \\
(0)\end{array}$ & 4.11 & .53 \\
\hline 12 & $\begin{array}{l}\text { The vocabulary acquisition techniques } \\
\text { made me realize the necessity of word } \\
\text { structure and context practice. }\end{array}$ & $\begin{array}{l}34.29 \\
(12)\end{array}$ & $\begin{array}{l}54.29 \\
(19)\end{array}$ & $\begin{array}{c}11.43 \\
(4)\end{array}$ & $\begin{array}{l}0 \\
(0)\end{array}$ & $\begin{array}{l}0 \\
(0)\end{array}$ & 4.23 & .65 \\
\hline 13 & $\begin{array}{l}\text { The vocabulary acquisition techniques } \\
\text { made me enjoy learning vocabulary. }\end{array}$ & $\begin{array}{c}14.29 \\
(5)\end{array}$ & $\begin{array}{l}68.57 \\
(24)\end{array}$ & $\begin{array}{c}17.14 \\
(6)\end{array}$ & $\begin{array}{l}0 \\
(0)\end{array}$ & $\begin{array}{c}0 \\
(0)\end{array}$ & 3.97 & .57 \\
\hline 14 & $\begin{array}{l}\text { The vocabulary acquisition techniques } \\
\text { offered variety in learning vocabulary. }\end{array}$ & $\begin{array}{c}22.86 \\
(8)\end{array}$ & $\begin{array}{l}68.57 \\
(24)\end{array}$ & $\begin{array}{l}8.57 \\
(3)\end{array}$ & $\begin{array}{l}0 \\
(0)\end{array}$ & $\begin{array}{l}0 \\
(0)\end{array}$ & 4.14 & .55 \\
\hline \multicolumn{9}{|c|}{ Mean levels: $\quad 1.00-1.49=$ very negative $\quad 1.50$} \\
\hline
\end{tabular}


Table 3 shows opinions of the 35 first-year students towards the instruction of vocabulary acquisition techniques. The three statements students agreed with the most were no. 1 with the mean score of 4.26 (The letters were clear and easy to read), followed by no.12 with the mean score of 4.23 (The vocabulary acquisition techniques made me realize the necessity of word structure and context practice). The third was no. 14 with the mean score of 4.14 (The vocabulary acquisition techniques offered variety in learning vocabulary). Statement no. 3 (The level of the content suited me) was agreed with the least, with the mean score of 3.69. What was mostly noticeable from the table was that very few students (only 7) disagreed with any item at all, and not a single item was strongly disagreed with.

Table 4 Descriptive Statistics of Students' Attitudes towards Instruction of Vocabulary Acquisition Techniques Shown in Category

\begin{tabular}{|l|l|c|c|c|}
\hline \multicolumn{1}{|c|}{ Category } & Mean & SD & Meaning \\
\hline 1 & format and content & 3.98 & .34 & positive \\
\hline 2 & activities & 3.99 & .40 & positive \\
\hline 3 & benefits & 4.10 & .40 & positive \\
\hline & Total & $\mathbf{4 . 0 3}$ & $\mathbf{. 3 0}$ & positive \\
\hline
\end{tabular}

The overall mean score of students' attitudes was 4.03 which can be interpreted as having a positive level of opinions on this instruction. As shown in Table 4 above, benefits from the vocabulary acquisition techniques were given the highest mean score from the students (4.10). Similarly, the other two categories, format and content and activities were given rather high mean scores (3.98 and 3.99 respectively).

\section{DISCUSSION AND CONCLUSION}

The research finding testifies to the assumption that the selected vocabulary acquisition techniques contributed to the students' improvement of vocabulary. This is probably because there were such various ways to acquire English words that students did not have to blindly stick to only one particular method of learning vocabulary. This variety may have to a very large extent helped encourage and simultaneously spice up the learning process. In addition, students appreciated the importance of vocabulary, that words are major building blocks for any language. That they had greatly benefited from the techniques provided is clearly shown in the progress they made in terms of the pretest and posttest scores. This finding was similar to other research work such as Emadin \& Moghadam (2007), Tabtimsai (2003) indicating that vocabulary learning techniques can help improve students' learning outcome. The result was also supported by their attitudes towards the benefits they felt they had received which was positively rated with the mean score at 4.10 . Moreover, they were also taught to apply any one appropriate technique out of these ten when they encountered an unfamiliar word to assure acquisition and retention.

The data obtained from the subjects provided sufficient reply for the research question one that the two main techniques including context clue analysis and word structure analysis were most likely to enhance the students' vocabulary learning due to the higher mean scores from the pre-and post-tests of the three proficient groups $($ high $=35.67: 41.33$, intermediate $=22.18: 34.00$, low $=14.67: 27.17$ ). The findings from this study suggested that the teachers strongly emphasize and explain more on techniques that students can apply to understand the meanings of unknown words in order to solve the problem of a limited vocabulary. This procedure can help lessen the difficulties when they read the text. Also, the researcher agreed with what Ellis (2002, p.179) suggested to be an important factor. This is frequency which is a fundamental feature of cognitive processing and acquisition. The words frequently seen tend to be remembered and learned. In this case, practice should be done in class through exercises or activities. Moreover, positive opinions on the instruction of in-class useful techniques were given by the subjects This finding is consistent with the findings reported by Tabtimsai (2003), who found that students reacted positively to the exercises and by Summat (2009), who found that the participants had positive attitude towards the use of task-based learning activities to improve the students' vocabulary learning and were confident that they could read and pronounce the target vocabulary after learning by themselves. 


\section{AUTHOR INFORMATION}

Mr. Wiwat Orawiwatnakul received his Bachelor of Art in English and Master of Arts in Literature from Chulalongkorn University, Thailand. Now he is a lecturer at Language Institute, Bangkok University. His main research interests include students' vocabulary learning process and learning strategies.

\section{REFERENCES}

1. Chin, Cheongsook. (2009). Influence of three teaching strategies on Korean EFL students' vocabulary development. Indian Journal of Applied Linguistics, 35(2), 113-118.

2. Ellis, N. (2002). "Frequency effects in language processing: A review with implications for theories of implicit and explicit language acquisition," Studies in Second Language Acquisition, 24 (2), 143-148.

3. Emadin, Ahmad \& Moghadam, Masoud Yazdani. (2007). The effect of teaching word formation knowledge on sentence restatement and inferencing.

4. Min, Hui-Tzu. (2008). EFL vocabulary acquisition and retention: Reading plus vocabulary enhancement activities and narrow reading language learning, 58 (1), 73-115.

5. Nagy, Williams E., and Others. (1992). Guidelines for Instruction in Structural Analysis. Technical Report No. 554 ( ED345207 ). Illinois University, Urbana. Center for the Study of Reading

6. Nation, I. (2001). Teaching and learning vocabulary. Cambridge: Cambridge University Press.

7. Pittman, William. (2003). Building vocabulary through prefixes, roots, and suffixes. Nagasaki University Faculty of Environmental Studies (Nagasaki, Japan). The Internet TESL Journal, 9(7), July.

8. Schmitt, N. (1997). "Vocabulary learning strategies," in Vocabulary: Description, Acquisition and Pedagogy. Cambridge: Cambridge University Press.

9. Summat, Natthanan. (2009). Using task-based activities to improve the students' vocabulary learning at Watsratong Municipal School. An Independent Study Report for the Master of Arts in English, Khon Kaen University.

10. Sun, Bing, and Zhou Rong. (2005). A research report on the senior high school students' use of contextual clues in lexical guessing. FLTA, 2, 49-54.

11. Tabtimsai, Khemika. (2003). The development of vocabulary learning strategies exercises for mathayomsuksa three students of Thamakavittthayakom School, Thamaka, Kanchanaburi. Master's Degree Thesis, Silapakorn University.

12. Torat, Sagiam. (2000). English textbook analysis. Bangkok: Silapakorn University Press.

13. Watson, T, R. (2003). "Memes and the teaching of English," in Essential Teachers. Winter 56.

14. Yang, Na. (2009). Context clues and contextual guessing. Sino-US English, ISSN 1539-8072, USA. May 2009, Volume 6, No.5 (Serial No. 65), 48-56.

15. Yeun, Joanna. (2009). Context clue detectives: Empowering students with a self-learning device through the teaching of context clues. Master's Degree. University of California. 


\section{NOTES}

